Development of an Outdoor Concentrating Photovoltaic Module Testbed, Module Handling and Testing Procedures, and Initial Energy Production Results

M. Muller

Technical Report NREL/TP-520-46569

September 2009

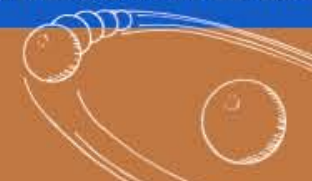




\section{Development of an Outdoor Concentrating Photovoltaic Module Testbed, Module Handling and Testing Procedures, and Initial Energy Production Results}

M. Muller

Prepared under Task No. PVD9.1410

Technical Report NREL/TP-520-46569

September 2009

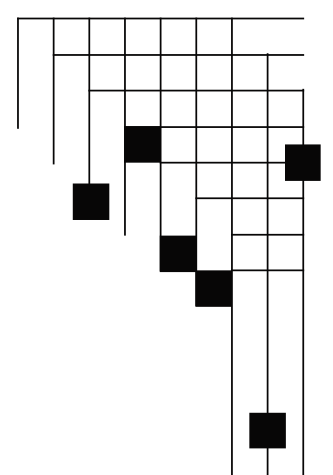




\section{NOTICE}

This report was prepared as an account of work sponsored by an agency of the United States government. Neither the United States government nor any agency thereof, nor any of their employees, makes any warranty, express or implied, or assumes any legal liability or responsibility for the accuracy, completeness, or usefulness of any information, apparatus, product, or process disclosed, or represents that its use would not infringe privately owned rights. Reference herein to any specific commercial product, process, or service by trade name, trademark, manufacturer, or otherwise does not necessarily constitute or imply its endorsement, recommendation, or favoring by the United States government or any agency thereof. The views and opinions of authors expressed herein do not necessarily state or reflect those of the United States government or any agency thereof.

Available electronically at http://www.osti.gov/bridge

Available for a processing fee to U.S. Department of Energy and its contractors, in paper, from:

U.S. Department of Energy

Office of Scientific and Technical Information

P.O. Box 62

Oak Ridge, TN 37831-0062

phone: 865.576 .8401

fax: 865.576 .5728

email: mailto:reports@adonis.osti.gov

Available for sale to the public, in paper, from:

U.S. Department of Commerce

National Technical Information Service

5285 Port Royal Road

Springfield, VA 22161

phone: 800.553.6847

fax: 703.605.6900

email: orders@ntis.fedworld.gov

online ordering: http://www.ntis.gov/ordering.htm 


\section{Table of Contents}

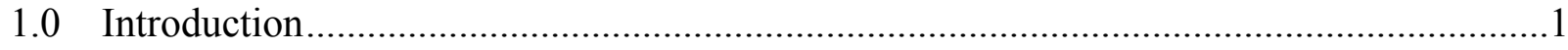

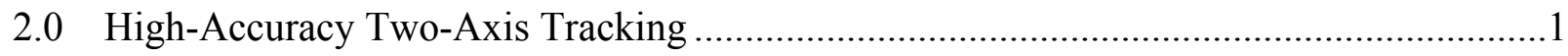

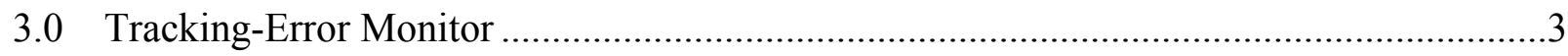

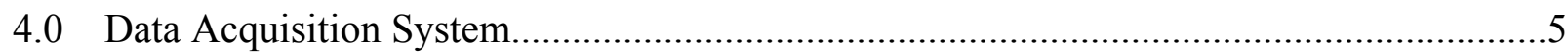

5.0 Module Handling and On-Sun Alignment Procedure.......................................................12

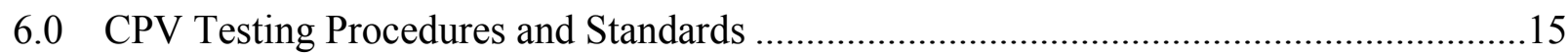

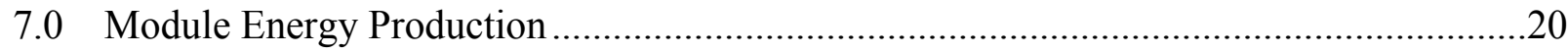

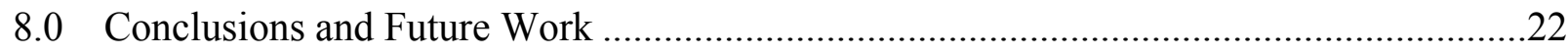

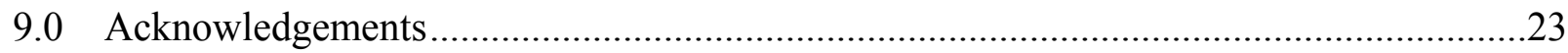

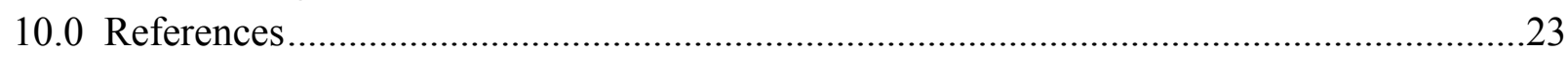

\section{List of Figures}

Figure 1. Tracking error with no control corrections (on June 29, 2008) ……….....................4

Figure 2. Tracking error with control corrections (on June 30, 2009) .....................................5

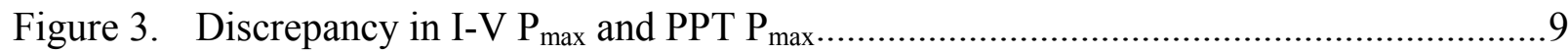

Figure 4. April 2009 peak power tracking error (before algorithm change) ............................10

Figure 5. April 2009 peak power tracking after algorithm change)........................................11

Figure 6. May 2009 peak power tracking error (after algorithm change)................................11

Figure 7. Sweep data, module previously aligned using a multimeter......................................14

Figure 8. Sweep data for module characterized in Fig. 7 after 0.1-degree trimming................14

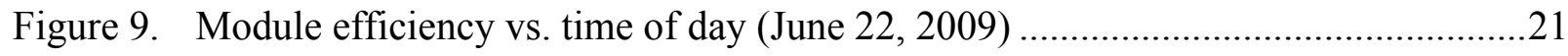

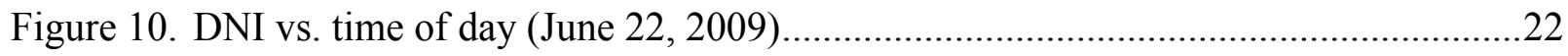

\section{List of Tables}

Table 1. Module Electrical Specifications Provided by CPV Companies................................6

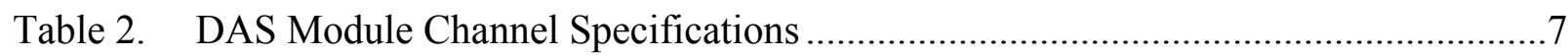

Table 3. Auto-Range Capabilities of DAS Channel ...............................................................

Table 4. Additional Measurements Built into Multi-Tracer .....................................................

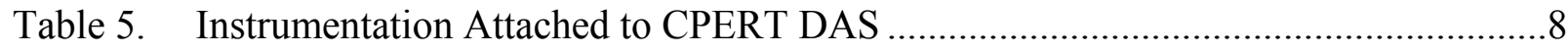

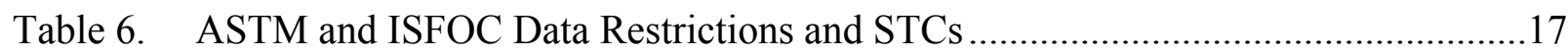

Table 7. Variable Definitions and Specifications for Triple-Junctions Cells ..........................18

Table 8. Module Power Ratings Based on ISFOC and ASTM Procedures .............................19

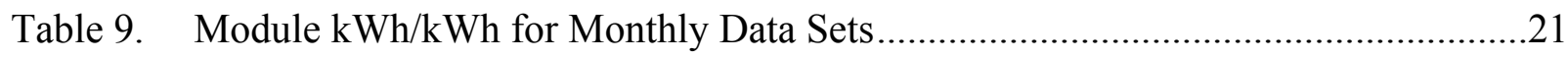




\subsection{Introduction}

In recent years, the concentrating photovoltaic (CPV) industry has rapidly expanded as many new companies have entered the market. Each company has a unique approach aimed at making CPV a reliable, low-cost alternative to traditional flat-plate photovoltaics (PV). As with other new technologies, a need arises to establish appropriate standards, testing requirements, and a better understanding of the technology itself. Solar Energy Technologies Program (SETP) money has been awarded to some of these manufacturers, and as a result, the Test and Evaluation group at the National Renewable Energy Laboratory (NREL) has been tasked with evaluating some of the associated deliverables. To achieve this task and fulfill the above needs, NREL's Test and Evaluation group made plans to build a testbed for CPV. This report addresses the issues associated with building a CPV testbed and presents initial results from module testing. In particular, there is a focus on high-accuracy two-axis tracking, monitoring tracking error, CPV data acquisition, module handling and testing procedures, and standards development. Finally, initial power ratings and efficiency results are presented.

\subsection{High-Accuracy Two-Axis Tracking}

This project began with plans to refurbish an existing two-axis tracker at NREL's Outdoor Test Facility (OTF) for use with CPV testing. As part of this process, many of the known CPV companies were contacted to understand what capabilities should be built into a CPV testbed at NREL. With regard to trackers, results indicate that high-concentration PV (HCPV) modules are being prototyped with acceptance angles ranging from 0.5 to 2 degrees. The acceptance angle is commonly defined as the angle of tracking error beyond which module power will drop below $90 \%-95 \%$ of the power produced at zero tracking error. Hereafter in this report, acceptance angle will use only the $95 \%$ value. It is typical for HCPV module power to fall rapidly to zero when the acceptance angle is exceeded. To isolate module performance from tracker performance, tracking error should be significantly less (ideally by an order of magnitude) than the given module's acceptance angle. This requirement leads to a secondary requirement to include in the data acquisition system — a means for measuring tracking error.

Acceptance angles of 0.5 degree suggest a need for a tracking that is accurate to 0.05 degree. Although ideal, this accuracy is unlikely with the existing tracking structure and tracking controller. Specifications for the gear drive and onsite measurements confirm that the gear drive has a backlash of about 0.05 degree, leaving no room for controller error.

Sun-tracking control can typically be grouped into three classifications: open-loop control, closed-loop control, and a hybrid between the two. Open-loop control refers to a controller that has no feedback of the targeted variable. In this case, it means that the controller has no feedback from the sun as to its pointing error. Basic open-loop control for sun tracking relies on 
a computation of the sun's position based on time of day, latitude, and longitude. The computed sun position is translated into the drive-system movements that are needed to achieve on-sun status. The controller has feedback from encoders on the drive system to determine if motors or other components have moved as needed to correctly point at the sun. Pointing errors can result from errors due to pedestal tilt, drive-system inconsistencies, clock error, and/or encoder/limit switch positions. Most open-loop controllers provide a means to calibrate out or correct for the above errors. Weaknesses of open-loop control are that calibrations/corrections may not eliminate sufficient error and there are no automatic corrections for error factors that may change with time.

Closed-loop control has knowledge/feedback of the sun's position from an appropriate sensor and therefore can constantly correct/calibrate itself. This direct feedback has the potential for very high-accuracy tracking when there is an unobstructed view of the sun. Feedback control has two major weaknesses for CPV. One, accurate tracking typically depends on the reliability of a single sensor. Two, all sun position sensors depend on a clear view of the sun. Clouds or overcast skies result in significant tracking error, and a delay time is necessary to find the sun when the sky becomes clear. Although this type of tracking could work from an energyproduction standpoint (CPV modules produce very little power when the sun is obstructed), it is not adequate for a CPV module research platform. It is very useful to analyze how a module performs under various solar conditions, and a complete data set can only be made available if the tracker is continuously pointing at the sun.

A hybrid controller provides the best of open-loop and feedback control. The sun is followed throughout the day based on open-loop calculations and position encoders; but when the irradiance is high enough (clear-sky conditions), high-accuracy control is provided through sunposition feedback. The sun-position sensor is basically used to fine-tune or calibrate out the errors that can be a part of open-loop control. Anecdotal evidence suggests that CPV companies typically choose between open-loop and hybrid control based on the acceptance angle of their modules.

In early 2008, the market was explored for controllers that could be used on NREL's tracker. Although Sandia National Laboratories did work in the late 1980s to help develop a flexible, high-accuracy controller that could be marketed in the $\$ 500$ price range [1], the current market still offers very little in terms of tracking control. Based on Sandia's research, an accurate openloop controller is available from Precision Solar Technologies in the $\$ 10,000$ price range. Many tracker companies have developed controllers that come as part of the tracker package, but are not made for individual sale. Inexpensive programmable-logic controllers, microprocessors, motor drivers, sensors, and other components are readily available to build a high-accuracy controller; but this, of course, comes with high initial development costs. Discussions with small CPV startups indicate that they have had to deal with these challenges when investigating tracking control options. Some companies indicated that they had decided to build their own 
controllers, whereas others had contracted with tracker companies to provide an entire package. Regardless of approach, there is little to no data or documentation in terms of tracking accuracy and long-term reliability. A project at Oak Ridge National Laboratory to develop indoor daylighting based on sun tracking encountered problems finding an off-the-shelf controller. Oak Ridge eventually decided to develop a controller to meet the project's needs, and some efforts have been made by Oak Ridge to make the controller available [2].

An off-the-shelf hybrid controller was considered the best option for NREL's testbed, but cost and lack of availability forced an investigation into other possibilities. The existing tracker had not been in operation for at least two years and no documentation could be found on its tracking performance. Therefore, a decision was made to use the existing controller to better characterize the hardware and structure before significant dollars were invested in a new controller. Handson experience and data collection would provide a true measure of the limitations of the existing structure, its drive system, and its controller. Fortunately, Advanced Thermal Systems, the original designer of the existing controller, is local to NREL and has been available to support efforts to bring the tracker back on line. The existing controller uses astronomical calculations to determine the sun's position within 0.01 degree and provides corrections for pedestal tilt, drivesystem errors, clock drift, and a daily reset of encoder position. A target was set to achieve a tracking accuracy of 0.25 degree with existing hardware and to explore options to improve accuracy as the system was better characterized.

\subsection{Tracking-Error Monitor}

Quantitatively documenting a tracking accuracy of 0.25 degree requires some type of device for actively measuring tracking error. In addition, the tight acceptance angles of some CPV modules require an accurate tracking-error measurement to filter tracking inadequacies from module performance data. Based on these needs, we made an extensive search to find a tracking-error monitor (TEM) that was accurate to 0.05 degree and within the budget constraints of this project. As a whole, we found that this type of product is not readily available. In 2008, Green Mountain Engineering released a product that uses sun imaging to achieve the desired accuracy, but the product has a price tag near $\$ 10,000$. Papers in the literature described a product by Inspira called SunDog [3]. Although the SunDog could have provided tracking-accuracy measurements, it did not appear as an item available to purchase. Communication with CPV companies indicated that many have had custom devices built for prototype testing. In the short-term, the search for a TEM led to a device built by Sandia that is described in Ref. [4]. Sandia was able to supply a monitor as described in the referenced report. The device was calibrated at Sandia and provides an accuracy of \pm 0.02 degree within a viewing angle \pm 1.8 degree for both azimuth and elevation measurements. Because Sandia was only able to provide one device and the tracking plane is large, we are considering having additional devices built that use off-the-shelf positionsensing detectors (PSDs) to measure the location of a projected sunspot—and hence, tracking 
error. Our initial investigation suggests that PSDs can be purchased and built into a TEM for under $\$ 1,500$.

Additional TEMs will be used to better quantify the performance of NREL's tracker. NREL's two-axis tracker has a steel torque tube that extends four feet out on each side of its pedestal. This torque tube, via steel forks, supports two test planes that are roughly 11 feet by 10 feet. The test planes consist of an easily configurable $80 / 20^{\mathrm{TM}}$ aluminum structure and aluminum I-beams. These specifications emphasize that there is the potential for flexing of test plane due to differing rates of expansion/contraction between steel and aluminum and from the structure acting as a large sail in the wind. Although these forces were considered during design and installation, mounting TEMs at various points in the plane will quantify the effect that flexing has on tracking accuracy. Having spare monitors on hand will also make continuous measurement of tracking error possible even when a monitor needs to be taken down for calibration. There is also a future need for CPV system data to expand models such as PVWatts and the Solar Advisor Model. The majority of these systems will be mounted at locations outside NREL, and portable TEMs will be invaluable in the field testing to come.

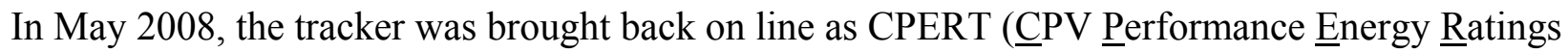
Test-bed) and was calibrated to track the sun. The Sandia TEM was mounted to the tracker and the data it provided over several months were used to recalibrate and improve tracking accuracy. Figure 1 provides an initial plot of tracking accuracy with no controller corrections.

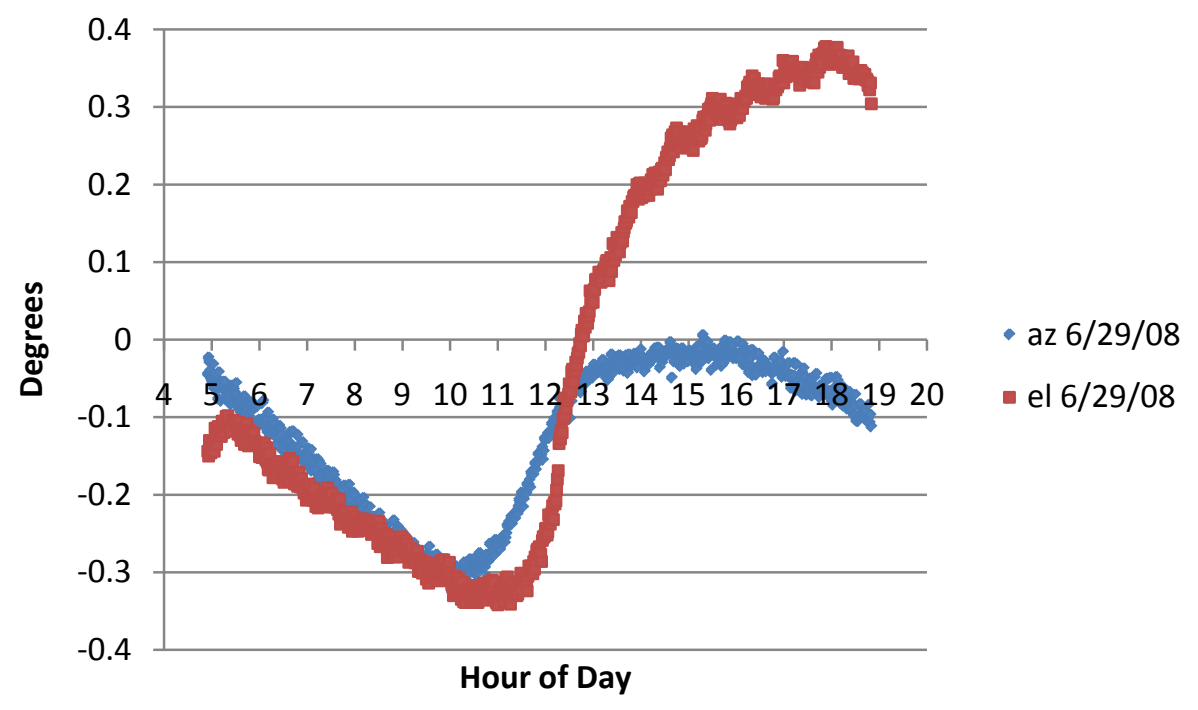

Figure 1. Tracking error with no control corrections (on June 29, 2008).

Over several months, control correction factors were adjusted to improve tracking accuracy to desired levels. Figure 2 shows that for almost the exact date a year later, the tracking error is well within \pm 0.15 degree (achieving the \pm 0.25 degree target) for both azimuth and elevation 
pointing. Although we think that tracking error could be further minimized, the process can be time consuming and perhaps unnecessary considering the tracking-error data can be used for filtering.

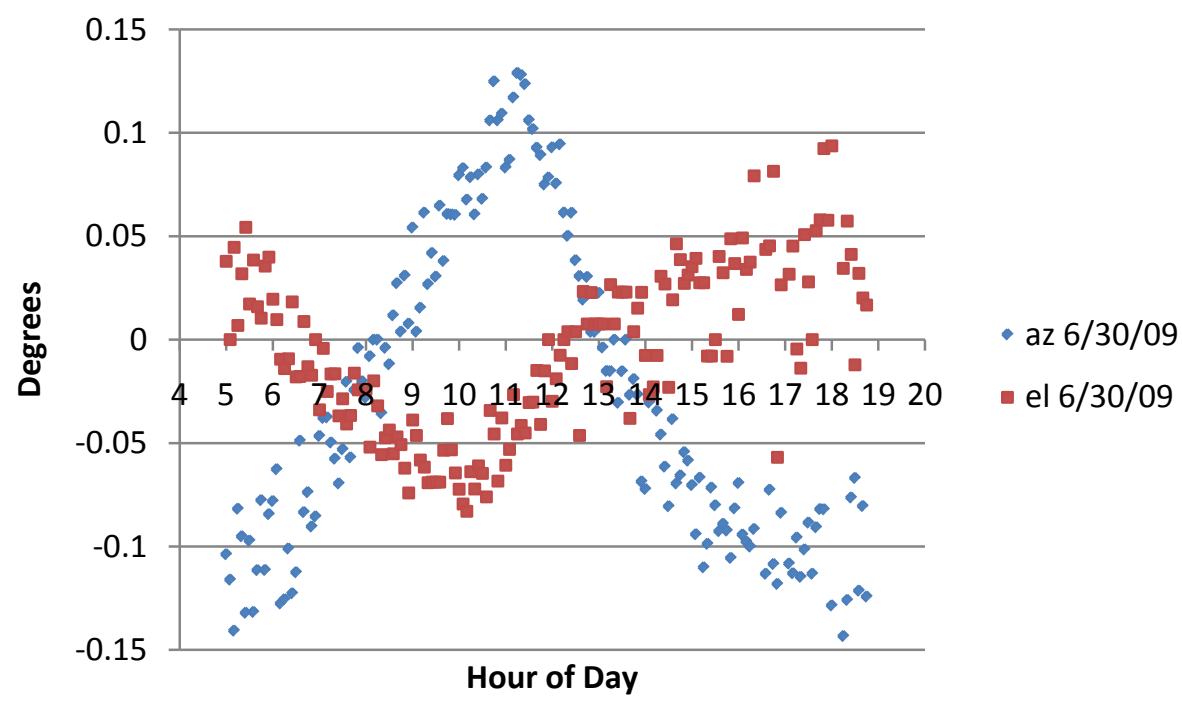

Figure 2. Tracking error with control corrections (on June 30, 2009).

It is also worth noting that NREL has become aware of a hybrid controller made by the Spanish company Suntrack. Initial investigations into Suntrack suggest that their controller would provide a good retrofit for the CPERT tracker. The cost is in the $\$ 1500$ range and provides the potential to improve tracking accuracy immediately after install.

Future plans are to purchase this controller and replace the more than 25-year-old components currently being used.

\subsection{Data Acquisition System}

Building a testbed for CPV modules requires coupling high-accuracy two-axis tracking with an appropriate data acquisition system (DAS). DAS design begins with considering what parameters need to be measured and how often they need to be measured. A desired data set for CPV modules includes voltage, current, power, and temperature for the module, coupled with tracking error, direct-normal irradiance (DNI), global-normal irradiance (GNI), ambient temperature, and wind speed. Although the meteorological parameters are fairly simple lowvoltage measurements, the electrical characteristics of the modules can get complicated. The project aims to characterize the short-term performance characteristics of various CPV technologies, as well as monitor degradation over longer periods of time. A multi-channel current-voltage (I-V) curve tracer that holds modules at peak power in between traces is an efficient means of meeting both these goals. 
Use of a multi-tracer presents two challenges when working with CPV modules. First, the unit must be located in close proximity to the modules to minimize wire length as needed for measuring short-circuit current. The only realistic way to keep module wire lengths under 40 feet was to locate the multi-tracer immediately next to the tracker pedestal. Most multi-tracers are located indoors - for protecting the unit and for using the large capacity of HVAC systems to regulate the temperature of the unit. In the case of CPERT, locating the unit outdoors and under the tracker meant building a small custom enclosure that would protect the unit from dust, rain, snow, and ice; provide the means of connecting to modules that are moving with the sun; and shed up to 3,200 watts of heat from modules under load. The second problem is that maximum power, voltage, and current must be specified for each channel of the unit. Because the CPV industry is young and rapidly changing, this requires establishing channel specifications for modules that are rapidly changing. The information obtained from the CPV manufacturers was used as a guide for setting channel specifications, and Table 1 summarizes some of the information from these companies.

Table 1. Module Electrical Specifications Provided by CPV Companies

\begin{tabular}{|l|l|l|l|l|l|l|}
\hline Module & $\mathbf{I}_{\mathbf{s c}}(\mathbf{A})$ & $\mathbf{V}_{\mathbf{~ o c}}(\mathbf{V})$ & $\mathbf{P}_{\mathbf{m p}}(\mathbf{W})$ & $\mathbf{I}_{\mathbf{s c}} \mathbf{x} \mathbf{1 . 3}$ & $\mathbf{V}_{\mathbf{o c}} \mathbf{x} \mathbf{1 . 2}$ & $\mathbf{P}_{\mathbf{m p}} \mathbf{x} \mathbf{1 . 2}$ \\
\hline 1 (existing) & 0.59 & 152 & 75 & 0.77 & 182.4 & 90 \\
\hline 2 (existing) & 0.9 & 290 & 200 & 1.17 & 348 & 240 \\
\hline 3 (existing) & 1.1 & 140 & 120 & 1.43 & 168 & 144 \\
\hline 4 (future) & 2.2 & 250 & 510 & 2.86 & 300 & 612 \\
\hline 5 (future) & 5.6 & 50 & 255 & 7.28 & 60 & 306 \\
\hline 6 (existing) & 7.3 & 3.1 & 20 & 9.49 & 3.72 & 24 \\
\hline 7 (existing) & 8 & 60 & 320 & 10.4 & 72 & 384 \\
\hline 8 (existing) & 8 & 18 & 150 & 10.4 & 21.6 & 180 \\
\hline 9 (future) & 11.2 & 50 & 510 & 14.56 & 60 & 612 \\
\hline
\end{tabular}

Most companies provide data for a DNI of $850 \mathrm{~W} / \mathrm{m}^{2}$, although Golden, Colorado, can have DNI values as high as $1,100 \mathrm{~W} / \mathrm{m}^{2}$. For this reason, Table 1 Includes short-circuit current $\left(\mathrm{I}_{\mathrm{sc}}\right)$ multiplied by 1.3 (1100/850), which was used as channel specifications were considered. Opencircuit voltage $\left(\mathrm{V}_{\mathrm{oc}}\right)$ has been multiplied by 1.2 to account for winter days, which can be significantly colder than standard test conditions yet will still have a high DNI. In summary, Table 1 shows the potential to have module electrical characteristics vary widely. The multitracer selected for the CPERT system is capped at 3,200 watts, which can be divided between 1-16 channels. In a best effort to plan for modules such as those listed above, the specifications were established as given in Table 2. 
Table 2. DAS Module Channel Specifications

\begin{tabular}{|c|c|c|c|c|c|}
\hline Channel \# & $\begin{array}{c}\text { Voltage } \\
\text { Max. (V) }\end{array}$ & $\begin{array}{c}\text { Current } \\
\text { Max. (A) }\end{array}$ & $\begin{array}{c}\text { Power } \\
\text { Max. (W) }\end{array}$ & $\begin{array}{c}\text { Resistance Max. } \\
\text { @ I I }\end{array}$ (ohms) & $\begin{array}{c}\text { Max Volts } \\
\text { @I I } \\
\text { sc } \% \text { FS) }\end{array}$ \\
\hline 1 & 80 & 15 & 600 & 0.035 & $0.7 \%$ \\
\hline 2 & 80 & 15 & 400 & 0.045 & $0.8 \%$ \\
\hline 3 & 80 & 15 & 400 & 0.045 & $0.8 \%$ \\
\hline 4 & 80 & 15 & 400 & 0.045 & $0.8 \%$ \\
\hline 5 & 200 & 8 & 400 & 0.060 & $0.2 \%$ \\
\hline 6 & 250 & 5 & 400 & 0.055 & $0.1 \%$ \\
\hline 7 & 250 & 5 & 600 & 0.050 & $0.1 \%$ \\
\hline
\end{tabular}

The DAS channels are able to auto range as listed in Table 3. The powers selected give CPERT the capability to handle modules up to a size of about 2 square meters, whereas auto ranging provides the capability to test most of modules seen in Table 1 .

Table 3. Auto-Range Capabilities of DAS Channel

\begin{tabular}{|c|c|c|c|c|c|}
\hline Measurements & Range & Common Mode & Resolution & Accuracy & Temp Co. \\
\hline \multicolumn{6}{|c|}{ Voltage@250 V F.S. (F.S. means "full scale") } \\
\hline & $250 \mathrm{~V}$ & $\pm 250 \mathrm{~V}$ & $7.6 \mathrm{mV}$ & $0.1 \%+0.02 \%$ & $50 \mathrm{ppm} /{ }^{\circ} \mathrm{C}$ \\
\hline & $25 \mathrm{~V}$ & $\pm 250 \mathrm{~V}$ & $760 \mu \mathrm{V}$ & $0.1 \%+0.02 \%$ & $50 \mathrm{ppm} /{ }^{\circ} \mathrm{C}$ \\
\hline & $2.5 \mathrm{~V}$ & $\pm 250 \mathrm{~V}$ & $76 \mu \mathrm{V}$ & $0.2 \%+0.04 \%$ & $50 \mathrm{ppm} /{ }^{\circ} \mathrm{C}$ \\
\hline \multicolumn{6}{|c|}{ Voltage@200VF.S. } \\
\hline & $200 \mathrm{~V}$ & $\pm 200 \mathrm{~V}$ & $6.1 \mathrm{mV}$ & $0.1 \%+0.02 \%$ & $50 \mathrm{ppm} /{ }^{\circ} \mathrm{C}$ \\
\hline & $20 \mathrm{~V}$ & $\pm 200 \mathrm{~V}$ & $610 \mu \mathrm{V}$ & $0.1 \%+0.02 \%$ & $50 \mathrm{ppm} /{ }^{\circ} \mathrm{C}$ \\
\hline & $2.0 \mathrm{~V}$ & $\pm 200 \mathrm{~V}$ & $61 \mu \mathrm{V}$ & $0.2 \%+0.04 \%$ & $50 \mathrm{ppm} /{ }^{\circ} \mathrm{C}$ \\
\hline \multicolumn{6}{|c|}{ Voltage @ 80 V F.S. } \\
\hline & $80 \mathrm{~V}$ & $\pm 80 \mathrm{~V}$ & $2.5 \mathrm{mV}$ & $0.1 \%+0.02 \%$ & $50 \mathrm{ppm} /{ }^{\circ} \mathrm{C}$ \\
\hline & $8.0 \mathrm{~V}$ & $\pm 80 \mathrm{~V}$ & $250 \mu \mathrm{V}$ & $0.1 \%+0.02 \%$ & $50 \mathrm{ppm} /{ }^{\circ} \mathrm{C}$ \\
\hline & $0.8 \mathrm{~V}$ & $\pm 80 \mathrm{~V}$ & $25 \mu \mathrm{V}$ & $0.2 \%+0.04 \%$ & $50 \mathrm{ppm} /{ }^{\circ} \mathrm{C}$ \\
\hline \multicolumn{6}{|c|}{ Current@15 A F.S. } \\
\hline & $15.0 \mathrm{~A}$ & NA & $460 \mu \mathrm{A}$ & $0.1 \%+0.02 \%$ & $50 \mathrm{ppm} /{ }^{\circ} \mathrm{C}$ \\
\hline & $1.5 \mathrm{~A}$ & NA & $46 \mu \mathrm{A}$ & $0.2 \%+0.04 \%$ & $50 \mathrm{ppm} /{ }^{\circ} \mathrm{C}$ \\
\hline \multicolumn{6}{|c|}{ Current@8AF.S. } \\
\hline & $8.0 \mathrm{~A}$ & NA & $245 \mu \mathrm{A}$ & $0.1 \%+0.02 \%$ & $50 \mathrm{ppm} /{ }^{\circ} \mathrm{C}$ \\
\hline & $0.8 \mathrm{~A}$ & NA & $25 \mu \mathrm{A}$ & $0.2 \%+0.04 \%$ & $50 \mathrm{ppm} /{ }^{\circ} \mathrm{C}$ \\
\hline \multicolumn{6}{|c|}{ Current@5 A F.S. } \\
\hline & $5.0 \mathrm{~A}$ & NA & $150 \mu \mathrm{A}$ & $0.1 \%+0.02 \%$ & $50 \mathrm{ppm} /{ }^{\circ} \mathrm{C}$ \\
\hline & $0.5 \mathrm{~A}$ & NA & $15 \mu \mathrm{A}$ & $0.2 \%+0.04 \%$ & $50 \mathrm{ppm} /{ }^{\circ} \mathrm{C}$ \\
\hline \multicolumn{6}{|l|}{ General Purpose } \\
\hline & $\pm 5 \mathrm{~V}$ & $\pm 5 \mathrm{~V}$ & $150 \mu \mathrm{V}$ & $0.1 \%+0.02 \%$ & $50 \mathrm{ppm} /{ }^{\circ} \mathrm{C}$ \\
\hline & $\pm 500 \mathrm{mV}$ & $\pm 5 \mathrm{~V}$ & $15 \mu \mathrm{V}$ & $0.1 \%+0.02 \%$ & $50 \mathrm{ppm} /{ }^{\circ} \mathrm{C}$ \\
\hline & $\pm 50 \mathrm{mV}$ & $\pm 5 \mathrm{~V}$ & $1.5 \mu \mathrm{V}$ & $0.2 \%+0.04 \%$ & $50 \mathrm{ppm} /{ }^{\circ} \mathrm{C}$ \\
\hline & $\pm 5 \mathrm{mV}$ & $\pm 5 \mathrm{~V}$ & $0.15 \mu \mathrm{V}$ & $0.3 \%+0.06 \%$ & $50 \mathrm{ppm} /{ }^{\circ} \mathrm{C}$ \\
\hline
\end{tabular}


The DAS has been in operation for nearly a year and thus far there have been no problems matching modules with available channels. It appears that the most likely problem with the DAS is going to be a shortage of channels, although the tracker will still have area for additional modules. With hindsight, the DAS may have been more accommodating if several of the 400watt channels had been split into two 200 -watt channels or four 100 -watt channels. Considering that all modules currently being tested are under 140 watts, it would have been possible to allot the DAS power to 10 to 12 channels and it may be retrofitted as such if deemed necessary.

The general-purpose channels and inputs for thermocouples that are listed in Table 4 provide a means of measuring and recording meteorological and temperature data along with module power characteristics.

Table 4. Additional Measurements Built into Multi-Tracer

\begin{tabular}{|c|c|c|}
\hline Description & \# Inputs & Notes \\
\hline Module Temps & 16 & Type T thermocouple \\
\hline Aux Temps & 8 & Type T thermocouple \\
\hline General Purpose & 8 & $\pm 5 \mathrm{~V}$ \\
\hline
\end{tabular}

Table 5 provides specifications for the equipment attached to the general-purpose channels. Additionally, a direct-normal spectroradiometer was installed at NREL's Solar Radiation Research Lab (SRRL) and these data are available from SRRL's data archives.

Table 5. Instrumentation Attached to CPERT DAS

\begin{tabular}{|c|c|c|}
\hline \multicolumn{3}{|c|}{ Kipp \& Zonen CHP1 pyrheliometer (DNI) } \\
\hline & Sensitivity $( \pm 0.5 \%)$ & $8.31 \mu \mathrm{V} / \mathrm{Wm}^{-2}$ \\
\hline & Response time to reach $95 \%$ final value & $5 \mathrm{~s}$ \\
\hline & Viewing angle & 5 degrees \\
\hline & Required tracking accuracy & \pm 0.5 degree \\
\hline \multicolumn{3}{|c|}{ Kipp \& Zonen CM11 pyranometer (GNI) } \\
\hline & Sensitivity & $5.1331 \mu \mathrm{V} / \mathrm{Wm}^{-2}$ \\
\hline & Response time to reach $95 \%$ final value & $5 \mathrm{~s}$ \\
\hline & Viewing angle & 180 degrees \\
\hline \multicolumn{3}{|c|}{ RM Young anemometer (Wind Sentry w/ voltage output) } \\
\hline & Range & $0-50 \mathrm{~m} / \mathrm{s}$ \\
\hline & Output signal over wind-speed range & $0-5 \mathrm{~V}$ \\
\hline & Threshold & $1.1 \mathrm{~m} / \mathrm{s}$ \\
\hline & Power requirement & 8-24 VDC 5mA@12 VDC \\
\hline \multicolumn{3}{|c|}{ Sandia Tracking-Error Monitor } \\
\hline & Azimuth constant $(\mathrm{K})$ & 8.27 \\
\hline & Elevation constant $(\mathrm{K})$ & 8.22 \\
\hline & Accuracy provided from Sandia calibration & \pm 0.02 degree \\
\hline & 4 output signals & $0-12 \mathrm{mV}$ \\
\hline & Calculation for error in degrees & $K(a-b) /(a+b)$ \\
\hline & Field of view & \pm 1.8 degrees \\
\hline
\end{tabular}


T-type thermocouples are used to measure one to three temperatures for each module, ambient temperature, and the temperature of the DAS box. The DAS box temperature and the wind speed are part of the data set, but are both also used as inputs to tracker stow functions. The tracker controller has a built-in capability to stow based on circuits that are monitored for an open/closed condition. A relay opens/closes the given circuit based on a specified wind speed and a specified temperature, and this in turn triggers the tracker to stow at a predetermined position. The wind stow is to protect the tracker and modules, whereas the temperature stow is used to ensure the DAS system does not exceed its maximum operating temperature. In the event that primary temperature controls for DAS box fail, a stow of the tracker eliminates heat to the box that is being generated by CPV modules.

The DAS software allows control of the interval for recording peak power tracking (PPT) data and for performing I-V sweeps and recording corresponding data. The PPT data are an average of the measurements taken over a specified interval, whereas the I-V data file records instantaneous measurements. Ideally, the PPT data provide a means to calculate the energy produced from a given module over a day, month, or longer interval, whereas the I-V data are useful for monitoring module performance, degradation, and troubleshooting failures. Currently, the DAS is set to sample PPT data every 5 seconds and average the data every minute, whereas $\mathrm{I}-\mathrm{V}$ curves are taken every five minutes. The PPT data provide a very useful record of changing meteorological conditions; but unfortunately, module PPT electrical measurements have not been accurate enough to use in calculating energy output. The DAS monitors and records PPT measurements as specified, but the actual algorithm for holding modules at peak power has periodically demonstrated inaccuracies. In many instances and in some cases for entire days, the peak power point from PPT data has not aligned with that from the corresponding I-V curve. Figure 3 displays an $\mathrm{I}-\mathrm{V}$ curve marked with its corresponding maximum power point $\left(\mathrm{P}_{\max }\right)$ and $\mathrm{P}_{\max }$ from the previous averaged minute of PPT.

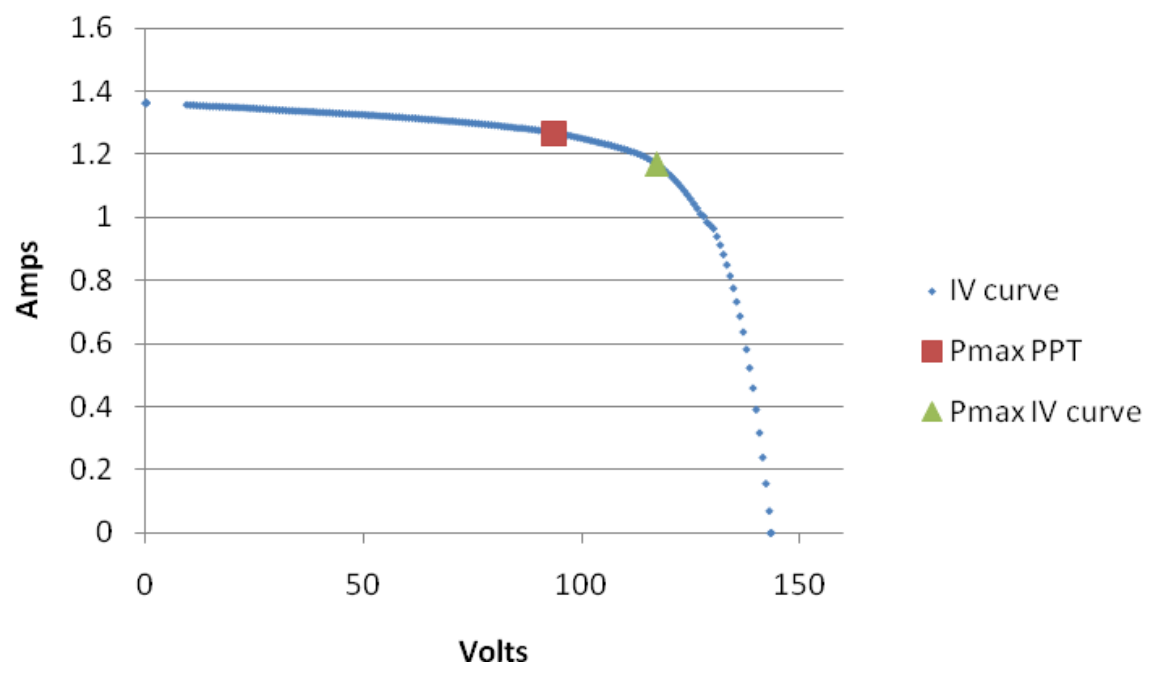

Figure 3. Discrepancy in I-V $P_{\max }$ and PPT $P_{\text {max }}$. 
PPT error is calculated by taking the difference between corresponding Pmax points, as exemplified in Fig. 3, and converting this to percent error. Due to limitations comparing 1minute average data with instantaneous data, peak power tracking error is only calculated when the DNI varied less than $2 \%$ in the 5 minutes prior to the IV curve. Figure 4 displays the peak power tracking error for one module/channel for data recorded in the first half of April.

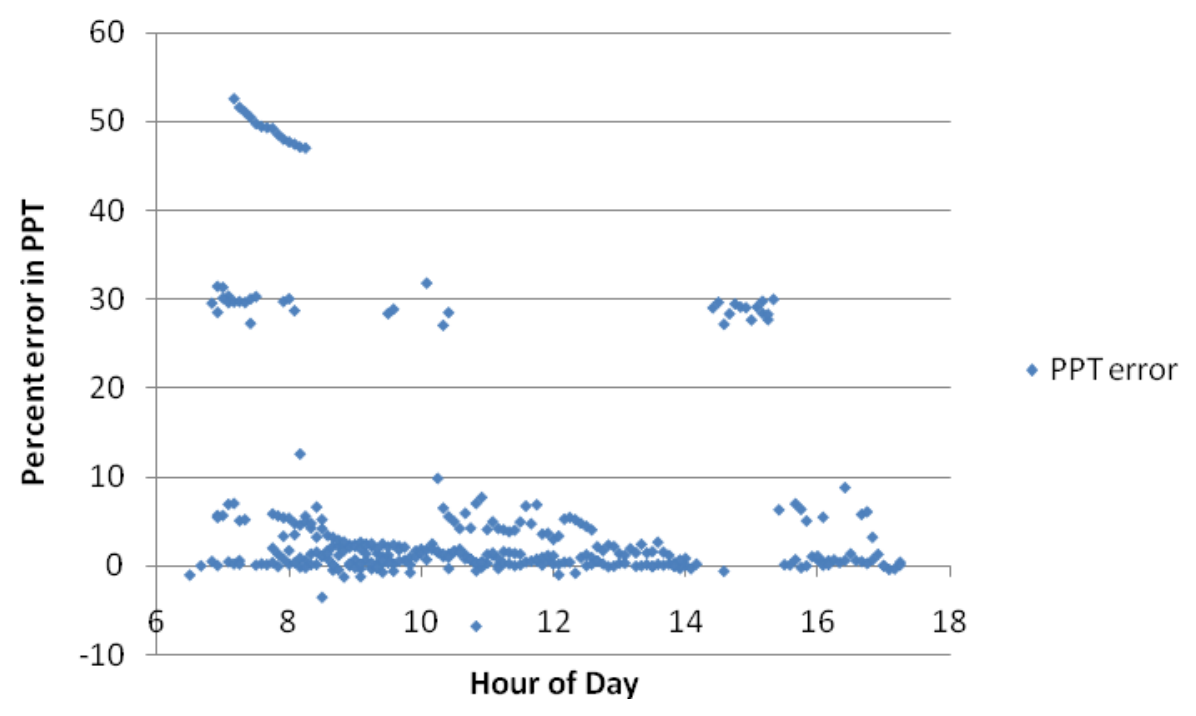

Figure 4. April 2009 peak power tracking error (before algorithm change)

Discussions with the DAS manufacture indicated that a step size used in the PPT algorithm may be causing problems. Generally speaking, the PPT algorithm uses a perturb-and-measure approach to find the peak power point. The initial perturbation is controlled by a preset step size that then shrinks as the algorithm hones in on the peak power point. If the initial step is too large, $\mathrm{V}_{\mathrm{oc}}$ could be reached and the algorithm would then start over. On the other side, if the step size becomes too small, finding $\mathrm{P}_{\max }$ can be lost in measurement noise. Regardless, in mid April, the manufacture made changes to the code to reduce the initial step size, and the primary results were promising. Figure 5 displays the PPT error for the same module/channel for the second half of April 2009 after the algorithm was changed. The maximum PPT error reduced from 52\% to $5 \%$ and the standard deviation for the PPT error data also reduced from $12.4 \%$ to $3.2 \%$. 


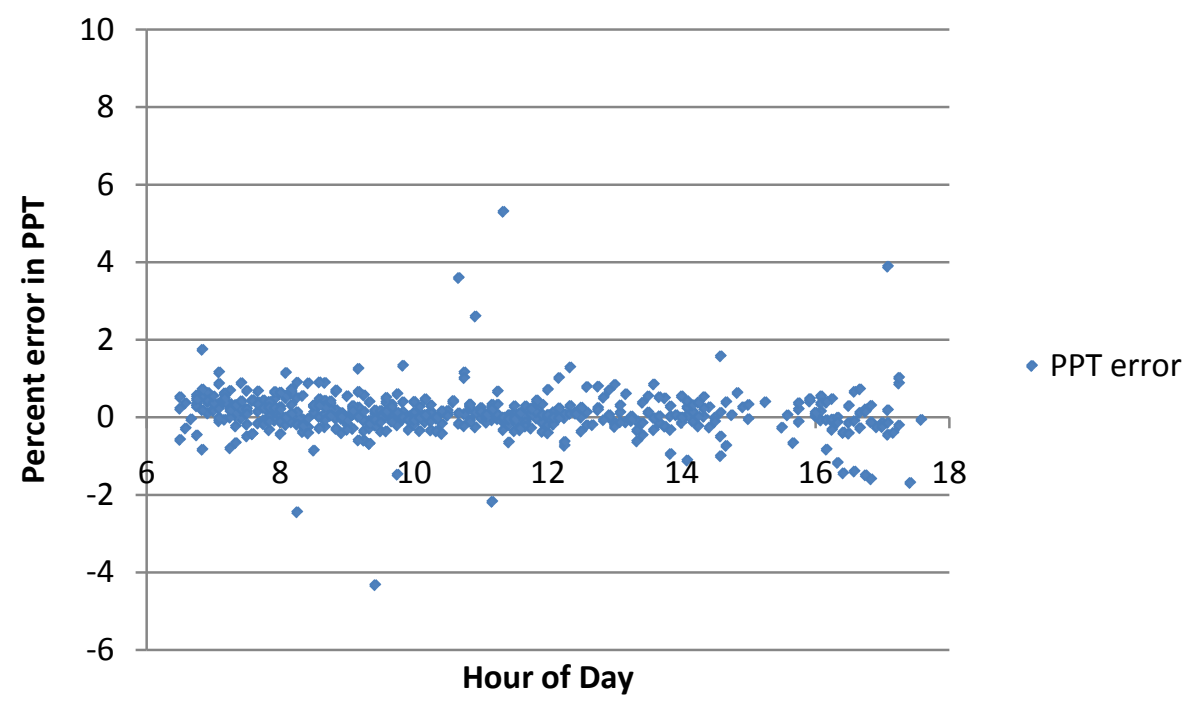

Figure 5. April 2009 peak power tracking error (after algorithm change).

To further monitor PPT, we examined data from both May and June 2009. The standard deviation of the PPT error was about 5\% in May and 6\% in June. Although this standard deviation is significantly lower than that of March and early April, it is still problematic for use in energy production calculations. Figure 6 presents the PPT error for May 2009, but it is also representative of the June 2009 data. In both months, high tracking errors $(10 \%-35 \%)$ are seen in the morning, but low errors in the afternoon.

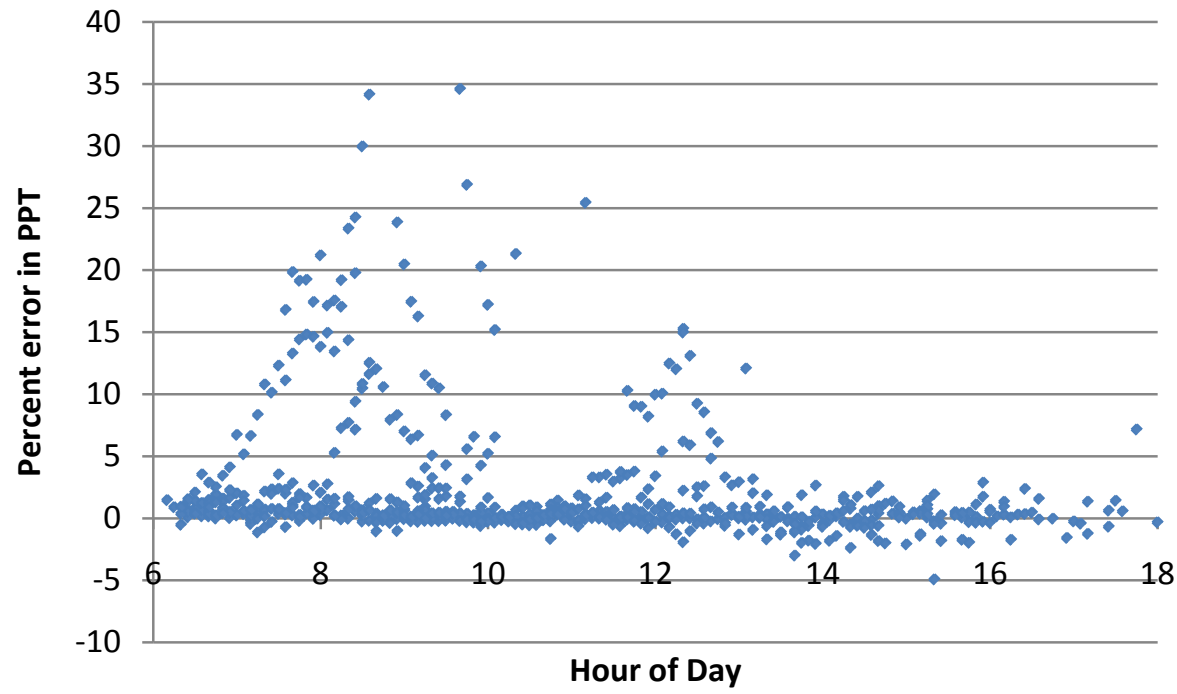

Figure 6. May 2009 peak power tracking error (after algorithm change). 
Future plans are to continue to study the tracking-error data and to work with the DAS manufacturer to mitigate the problem. It is of particular interest to understand if there are any special considerations CPV presents in regard to PPT algorithms, because the effectiveness of grid-connected inverter operation may be impacted. As a result of these problems, the PPT data set is currently only used to provide meteorological information, whereas the I-V data set is used to study the electrical characteristics of modules under test.

\subsection{Module Handling and On-Sun Alignment Procedures}

The first two CPV modules (a test and a control) to be dedicated to the CPERT system arrived in February 2009. At that point, a module-handling plan had been discussed and was basically as follows:

1) Inspect the module for visual defects or damage.

2) Consider points where water could enter the module if the tracker stowed in an upside-down position. Mitigate these possibilities with the permission of the manufacturer. (Not all trackers stow upside down.)

3) Consider other possible failures that could occur due to not being mounted with manufacturer's hardware and tracker. Mitigate concerns.

4) Match module electrical characteristics with a DAS channel.

5) Replace module connectors with MC2 connectors, if necessary.

6) Adjust $80 / 20^{\mathrm{TM}}$ mounting plane to accommodate module and fabricate any additional hardware needed for mounting.

7) Wait for periods with a clear view of the sun to mount the module.

8) Trim the tracker as needed to ensure less than 0.05 degree of tracking error.

9) Align the module with the sun using one of the following procedures:

a. Attach a multimeter to the module and trim to achieve maximum $\mathrm{I}_{\mathrm{sc}}$.

b. If the module has a sunspot and target, visually align.

c. After basic mount, run a tracker sweep while recording I-V curves.

10) Use electrical data and tracking error to determine if additional module trimming is needed. Trim and perform a verification tracker sweep. 
With modules in hand, steps 1-6 can be followed with few problems, but once it is time to mount the module it gets more difficult. Weather patterns can change quickly in Colorado and experience has shown that it can take on the order of an hour to mount and align a module with the sun. Often, it was clear and sunny when mounting began; but by the time $\mathrm{I}_{\mathrm{sc}}$ measurements could be taken, clouds or haze had obstructed the sun. So far, it appears that most modules are not built with a sunspot and target to simplify alignment. In some cases, modules were roughly aligned to the sun, but a fine tuning of the alignment had to wait multiple weeks due to poor weather conditions. Using $\mathrm{I}_{\mathrm{sc}}$ maximization to fine-tune modules with acceptance angles less than 0.5 degree also proved to be very difficult. Attempts were made to hit the maximum $\mathrm{I}_{\mathrm{sc}}$ within $2 \%$ for these modules, but tracker movement or slight changes in irradiance resulted in an $\mathrm{I}_{\mathrm{sc}}$ variation that was greater than $2 \%$. After experience with several modules, the lessons learned point to the following steps for more accurately mounting and aligning a module:

1) If possible with the given module size and weight, fabricate mounting brackets with three mounting bolts that are floating on springs. Simple turning of these bolts allows for tuning in azimuth or elevation. A particular module was delivered with holes for three-point mounting and this proved to speed the sun-alignment procedure and provide more accurate tuning. Unfortunately, not all modules facilitate this approach.

2) Mount the module when there is available time. The accuracy of the tracker plane dictates a pointing accuracy of about 0.2 degree. Note in the data log that the module has not been accurately aligned if sun was not available. Fine tuning can be done more quickly when the sun appears now that initial mounting is complete.

3) If the sun is only appearing for short periods each day, some fine tuning can be achieved by trimming to $\mathrm{I}_{\mathrm{sc}}$ measurements.

4) Accurate fine tuning can be achieved when clear skies are available for an hour or longer in the 4 hours surrounding solar noon. With narrow acceptance-angle modules, fine tuning should be done using tracker sweeps and measurements taken with the DAS.

As mentioned in the last step for module mounting, tracker sweeps were found to be the most accurate method for aligning modules with the sun. It is worthwhile to provide additional details of this process and present some of the data that have been generated. The existing controller provides the ability to track off sun by a specified offset command for azimuth and/or elevation. The idea is to sweep through a range of azimuth and elevation tracking errors that is in the range of the module's acceptance angle. This must be done within an hour time period that the irradiance is very stable (within two hours of solar noon and no clouds or haze). The faster the sweep can be performed and measured the better because this reduces variation in $\mathrm{I}_{\mathrm{sc}}$ due the time-dependent changes in DNI. For most modules, sweeping a sun-pointing error of \pm 1 degree in both azimuth and elevation is adequate for trimming a module. 
This process also provides a measurement of the module's acceptance angle, but is limited to \pm 2 degrees because the TEM no longer gives accurate measurement outside this range. The DAS is capable of taking I-V curves every minute; therefore, this is the shortest time interval that can be used to update the tracker offset as the sweep is performed. If the sweep is from -1 degree to 1 degree in 0.1-degree increments, it then takes 21 minutes to perform a sweep in azimuth or in elevation. If this test sweep is performed under clear skies near solar noon, then the variation in DNI should be less than or equal to $1 \%$. If it is necessary to shorten the sweep time, the tracking offset values can be more carefully chosen around the module's acceptance angle. Figure 7 displays the results from a sweep taken on a module that had been previously trimmed using $\mathrm{I}_{\mathrm{sc}}$ measurements from a multimeter. The results indicate that the module has an acceptance angle of about \pm 0.25 degree, but that elevation alignment is off by about 0.1 degree. (For perspective, it only takes 24 seconds for the sun position to change by 0.1 degree.)

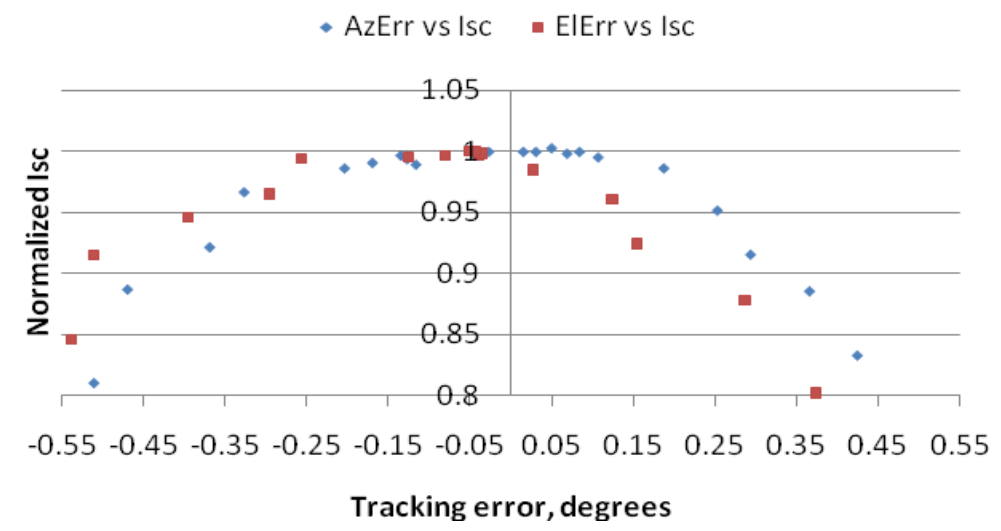

Figure 7. Sweep data, module previously aligned using a multimeter.

The module presented in Fig. 7 was trimmed by an additional 0.1 degree and then another sweep was performed. The results of the second sweep are shown in Fig. 8.

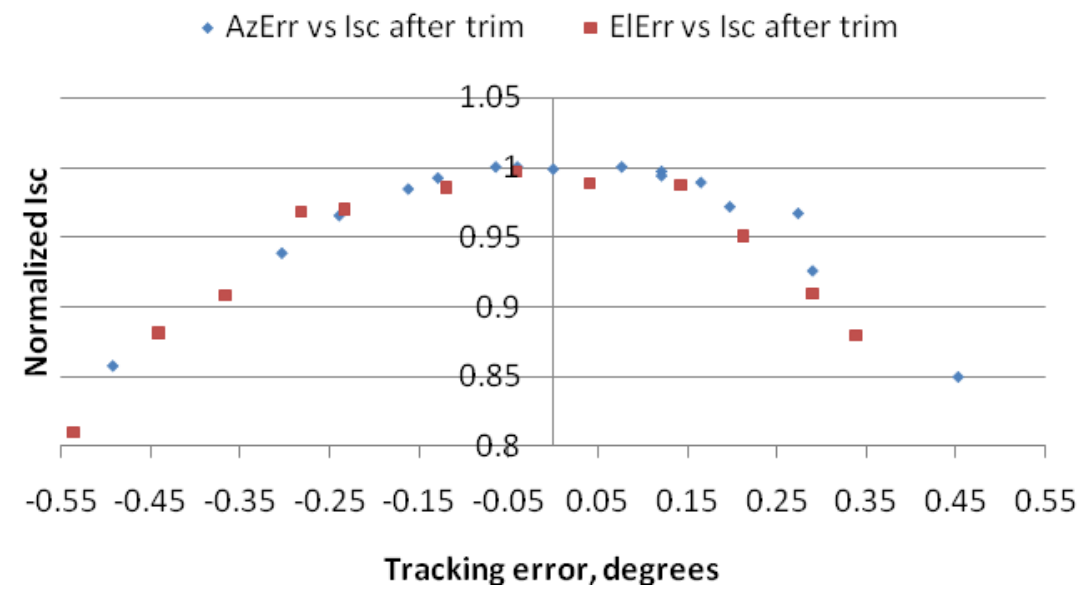

Figure 8. Sweep data for module characterized in Fig. 7 after 0.1-degree trimming. 
The second sweep confirms that the module is aligned to the sun with an acceptable accuracy. Results from other modules demonstrated similar results and so far the sweep procedure provides the best means to accurately align modules on sun. At this point the procedure requires manual inputs to the controller over the course of 45 minutes and then analysis of the data. Future work may consider taking steps to automate this sequence in the controller code.

\subsection{CPV Testing Procedures and Standards}

As communication began with companies about sending CPV modules to NREL, discussions occurred as to what procedures would be followed for CPV testing. Because the CPV industry is so young, little precedent could be found. Typically, when a flat-plate module arrives, the measurements and characterization $(\mathrm{M} \& \mathrm{C})$ group measures I-V curves under standard reference conditions, and a report is provided after indoor testing is completed for the module. In the case of CPV modules, indoor measurement protocols have not yet been established. Any CPV modules received by the $\mathrm{M} \& \mathrm{C}$ group have been mounted directly on a tracker, and I-V data have been taken over the course of a month or two. These data are then filtered to some degree before a performance report is generated using ASTM E 2527-06 to characterize module power. Although ASTM E 2527 can be used to rate CPV module power, at this time the CPV industry is far from consensus on standards for rating CPV for power or energy output. IEC 62108 (a qualification standard for $\mathrm{CPV}$ ) does provide some reference to outdoor testing and a working group has been meeting regularly to develop an IEC standard for performance and energy ratings.

It is worthwhile to examine the various standards being considered by the CPV industry and consider how data collected at NREL can aid this process. It is useful to consider how realistic it is to collect the data and follow the proposed procedures. On a more analytical level, the results generated by each procedure can be documented and compared against one another.

A good starting point is to examine the outdoor testing called for in the IEC 62108 qualification standard. A side-by-side (control module and test module) I-V measurement is to be taken both before and after the test module has been subjected to stress testing. The objective is to see if the test module has dropped in power output relative to the control due to stress testing. This procedure calls for the following conditions to be met before and during the I-V test sequence:

- $\mathrm{DNI}>700 \mathrm{~W} / \mathrm{m}^{2}$ and DNI variation $<2 \%$ for any 5 -minute interval

- No clouds/haze in a 45-degree angle around the sun

- Wind $<6 \mathrm{~m} / \mathrm{s}$ and no gusts $>10 \mathrm{~m} / \mathrm{s}$ in 10 -minute interval before a measurement

- Module temperature variation $<2^{\circ} \mathrm{C}$ in any 1 -minute interval

- $\mathrm{I}_{\mathrm{sc}}$ drop no more than $2 \%$ from maximum value due to misalignment. 
Although it may sound straight forward to mount two modules on a clear day and perform a couple I-V sweeps, experience at NREL has demonstrated that this can be time consuming to complete. First, as has been discussed in this report, aligning a module with the sun to within $2 \%$ of the maximum $I_{\mathrm{sc}}$ can require mounting the module and then commanding the tracker through an azimuth and elevation sweep. This procedure requires a mid-day time slot with clear skies for up to an hour. Depending on location and the time of year, this could take weeks to achieve. The same is true for waiting for the clear skies, low wind, and the stable temperature needed to take just two I-V curves.

This project is not currently geared toward qualification testing, but there is an interest in monitoring long-term degradation. In some cases, manufacturers are sending NREL both a test module and control module. In this event, plans are to use a similar, but alternative, procedure to that of IEC 62108. The test and control modules are mounted side-by-side by the procedure documented in the mounting section of this document. After successful mounting, the modules are left under the control of the DAS previously described. The modules are left on sun for about two weeks, of which at least one day has clear skies for at least one hour in a 4-hour period surrounding solar noon. The data are filtered to meet the DNI, wind, and temperature requirements. No visual observations or pictures are available to verify that there are no clouds within 45 degrees around the sun, but the data are rejected if the diffuse radiation (GNI-DNI) is greater than $140 \mathrm{~W} / \mathrm{m}^{2}$. The data remaining after filtering are used to calculate the relative power between modules. Multiple data points provide for multiple calculations that then are averaged. This procedure has currently been used when modules initially arrive at NREL, and plans are to repeat the procedure annually to separate on-sun degradation from degradation mechanisms that may occur in the dark.

An additional procedure in IEC 62108 requires that a CPV module be on sun for $1,000 \mathrm{kWh} / \mathrm{m}^{2}$ of cumulative DNI, excluding time periods when the DNI is less than $600 \mathrm{~W} / \mathrm{m}^{2}$. The test requires that the module be under load and tracking the sun. After the cumulative DNI is achieved, the module should have no major visual defects and power degradation should be no more than $7 \%$. Modules are currently mounted on sun and are accumulating DNI hours on the CPERT testbed. It is still unknown as to how long this process will take and how module power should be defined to characterize the degradation. Future reports will document the average number of days needed to achieve $1,000 \mathrm{kWh} / \mathrm{m}^{2}$ of cumulative DNI at NREL and what methods are chosen to report power degradation.

In late 2008, the IEC TC82 working group 7 (WG7) was considering several possibilities for power rating, but the consensus was to gather data before narrowing down the choices. In an effort to support WG7 efforts, NREL CPERT data are being used to compare ASTM E 2527 with a procedure used at the Instituto de Sistemas Fotovoltaicos de Concentracion (ISFOC) in Spain. 
The ASTM procedure calls for measurement of DNI, ambient temperature $\left(\mathrm{T}_{\mathrm{amb}}\right)$, wind speed (W), and $\mathrm{P}_{\max }\left(\mathrm{P}_{\mathrm{m}}\right)$ under specific conditions listed in Table 6. This set of measurements is to be repeated at least 20 times, and then a multiple linear regression is run on the data as given by Eq. 1, where $\mathrm{a}_{1}$ through $\mathrm{a}_{4}$ are the coefficients of the regression:

$$
P_{\max }=D N I\left(a_{1}+a_{2} D N I+a_{3} T_{a m b}+a_{4} W\right) .
$$

If the standard error of the power estimate is greater than $3 \%$, the data are rejected and the process is repeated. If the standard error is acceptable, the ASTM standard test conditions in Table 6 are substituted into Eq. 1 and the module power is calculated.

The ISFOC procedure calls for measurement of DNI, heat-sink temperature, wind speed, and I-V curves under the specific conditions listed in Table 6 [5]. At least fifteen I-V curves are to be taken, and then each I-V data pair is to be translated to ISFOC standard test conditions given in Table 6.

Table 6. ASTM and ISFOC Data Restrictions and STCs

\begin{tabular}{|c|c|}
\hline ASTM E 2527 Standard test conditions & ISFOC Standard test conditions \\
\hline Ambient Temperature $\quad\left(20^{\circ} \mathrm{C}\right)$ & Cell Temperature $\quad\left(60^{\circ} \mathrm{C}\right)$ \\
\hline Wind Speed & (no requirement) \\
\hline$\left(850 \mathrm{~W} / \mathrm{m}^{2}\right)$ & $\left(850 \mathrm{~W} / \mathrm{m}^{2}\right)$ \\
\hline ASTM E 2527 Data restrictions & ISFOC Data restrictions \\
\hline No visible clouds within $10^{\circ}$ of sun & No clouds immediately around sun \\
\hline $\mathrm{DNI}>750 \mathrm{~W} / \mathrm{m}^{2}$ & DNI $>700 \mathrm{~W} / \mathrm{m}^{2}$, also check for stability \\
\hline Ambient temperature within $10^{\circ}-30^{\circ} \mathrm{C}$ & Thermal stabilization of module \\
\hline $\begin{array}{l}\text { Average wind speed for previous } 5 \text { minutes does } \\
\text { not exceed } 5 \mathrm{~m} / \mathrm{s}\end{array}$ & $\begin{array}{l}\text { Average wind speed for previous } 5 \text { minutes does } \\
\text { not exceed } 3.3 \mathrm{~m} / \mathrm{s}\end{array}$ \\
\hline Minimum of 20 data points & Minimum of $15 \mathrm{I}-\mathrm{V}$ curves \\
\hline
\end{tabular}

Equations 2, 3, and 4 are used to translate the I-V data pairs to standard test conditions in Table 6. Table 7 provides definitions for the variables used and also provides specifications for typical triple-junction cells. These triple-junction specifications are used in all NREL calculations regardless of module manufacturer. Although ISFOC's procedure allows for making generalized assumptions for cell specifications, it is preferred that the manufacturer provide specifications for the cells being used [6].

$$
\begin{aligned}
& V_{\text {trans }}=V_{\text {measure }}+N_{\text {cells }} \frac{0.0257 \times\left(T_{S T C}-T_{\text {cell,measure }}\right)}{297}\left[\ln \left(\frac{\left(I_{S C, 1}-I_{\text {measure }}\right)\left(I_{S C, 2}-I_{\text {measure }}\right)\left(I_{S C, 3}-I_{\text {measure }}\right)}{I_{S C, 1} I_{S C, 2} I_{S C, 3}}\right)\right] \\
& +\left[N_{\text {cells }}\left(E_{g 1}+E_{g 2}+E_{g 3}\right)-V_{\text {oc,measure }}\left(1-\frac{T_{S T C}}{T_{\text {cell,measure }}}\right)\right.
\end{aligned}
$$




$$
\begin{aligned}
& I_{\text {trans }}=I_{\text {measure }} * \frac{D N I_{S T C}}{D N I} \\
& T_{\text {cell,measure }}=T_{h-s}+D N I \cdot R_{t h, s y s}
\end{aligned}
$$

Table 7. Variable Definitions and Specifications for Triple-Junctions Cells

\begin{tabular}{|l|l|}
\hline \multicolumn{2}{|c|}{$\begin{array}{c}\text { Assuming triple-junction cells GaInP, GaAs, Ge with current densities } 12.3,15, \text { and } 20 \mathrm{~mA} / \mathrm{cm}^{2}, \\
\text { respectively (assume spectral conditions are such that GaInP is the current-limiting junction) }\end{array}$} \\
\hline STC & Standard Test Conditions (See Table 6$)$ \\
\hline DNI & Direct-normal irradiance measurement $\left(\mathrm{W} / \mathrm{m}^{2}\right)$ \\
\hline $\mathrm{DNI}_{\mathrm{STC}}$ & DNI at STC, which is $850 \mathrm{~W} / \mathrm{m}^{2}$ \\
\hline $\mathrm{E}_{\mathrm{g} 1}$ & Bandgap for the top junction, assumed to be $1.85 \mathrm{eV}$ \\
\hline $\mathrm{E}_{\mathrm{g} 2}$ & Bandgap for the second junction, assumed to be $1.425 \mathrm{eV}$ \\
\hline $\mathrm{E}_{\mathrm{g} 3}$ & Bandgap for the third junction, assumed to be $0.66 \mathrm{eV}$ \\
\hline $\mathrm{I}_{\text {trans }}$ & Translation of measured current to STC $(\mathrm{A})$ \\
\hline $\mathrm{I}_{\text {measure }}$ & Single current measurement from the $\mathrm{I}-\mathrm{V}$ curve $(\mathrm{A})$ \\
\hline $\mathrm{I}_{\mathrm{sc}, \text { measure }}$ & Short-circuit current from the measured I-V curve $(\mathrm{A})$ \\
\hline $\mathrm{I}_{\mathrm{sc}, 1}$ & $\mathrm{I}_{\mathrm{sc}}$ for the top junction of the solar cell, $\rightarrow \mathrm{I}_{\mathrm{sc}, 1}=\mathrm{I}_{\mathrm{sc}, \text { measure }}(\mathrm{A})$ \\
\hline $\mathrm{I}_{\mathrm{sc}, 2}$ & $\mathrm{I}_{\mathrm{sc}}$ for the $2^{\text {nd }}$ junction of the solar cell, $\rightarrow \mathrm{I}_{\mathrm{sc}, 2}=\mathrm{I}_{\mathrm{sc}, \text { measure }}\left(\frac{\text { junction } 2 \text { current }}{\text { junction } 1 \text { current }}\right)(\mathrm{A})$ \\
\hline $\mathrm{I}_{\mathrm{sc}, 3}$ & $\mathrm{I}_{\mathrm{sc}}$ for the $3^{\text {rd }}$ junction of the solar cell, $\rightarrow \mathrm{I}_{\mathrm{sc}, 3}=\mathrm{I}_{\mathrm{sc}, \text { measure }}\left(\frac{\text { junction } 3 \text { current }}{\text { junction } 1 \text { current }}\right)(\mathrm{A})$ \\
\hline $\mathrm{N}_{\text {cells }}$ & Number of cells in series for the module under test \\
\hline $\mathrm{P}_{\text {trans }}$ & Translated power, which is the product of $\mathrm{I}_{\text {trans }}$ and $\mathrm{V}_{\text {trans }}(\mathrm{W})$ \\
\hline $\mathrm{R}_{\text {th,sys }}$ & Thermal resistance between the heat sink and the cell $\left({ }^{\circ} \mathrm{C} /\left(\mathrm{W} / \mathrm{m}^{2}\right)\right)$ \\
\hline $\mathrm{T}_{\mathrm{h}-\mathrm{s}}$ & Measured temperature of the heat sink or back plate of the module $\left({ }^{\circ} \mathrm{C}\right)$ \\
\hline $\mathrm{T}_{\mathrm{STC}}$ & Temperature of the cells at STC $\left(60^{\circ} \mathrm{C}\right)$ \\
\hline $\mathrm{T}_{\text {cell,measure }}$ & Cell temperature as calculated from a heat sink temperature measurement $\left({ }^{\circ} \mathrm{C}\right)$ \\
\hline $\mathrm{V}_{\text {trans }}$ & Translation of measured voltage to STC $(\mathrm{V})$ \\
\hline $\mathrm{V}_{\text {measure }}$ & Single voltage measurement from the I-V curve $(\mathrm{V})$ \\
\hline $\mathrm{V}_{\text {oc,measure }}$ & Open-circuit voltage from the measured I-V curve $(\mathrm{V})$ \\
\hline
\end{tabular}

It should also be noted that the procedure used at ISFOC is a method for rating CPV power at the system level; but in this report, it is being applied at the module level.

Both the ASTM and the ISFOC procedures presented some difficulties and neither was followed to exact specifications. In both cases, it is expected that measurements will be taken over a short period of time when an individual is present to verify there are clear skies around the sun. Although this is possible, it is labor intensive and deemed outside of the scope of this work.

For all modules on the CPERT testbed, the DAS was connected and left to automatically collect data. As an alternative to visual verification of clear skies, filtering is applied to the data set. 
The DNI is examined for the 5-minute period prior to execution of an I-V curve. If the DNI varies more than $2 \%$ during this period, the data point is filtered out. This is assumed to remove time periods when clouds are passing by the sun and also provides one of the checks on stability that the ISFOC procedure requires. In attempts to filter out hazy conditions, data are excluded if the diffuse radiation (GNI-DNI) is greater than $140 \mathrm{~W} / \mathrm{m}^{2}$. Rather than using just 15 or 20 data points, the data set is analyzed in monthly blocks, which can easily be more than 1,000 points. A larger data set will provide a more statistically valid analysis assuming filtering ensures that the specified test conditions are met. We expect that the standard deviation will increase with the larger data set if there are other variables driving module power that are not included in the analysis. The data set has also been filtered to meet required DNI thresholds, caps on average wind speed, and the ASTM ambient temperature range. In addition, tracker pointing error was limited to 0.15 degree. The ISFOC procedure requires thermal stability of the module, but does not quantify this specification. Module temperature was restricted to a variation of $2^{\circ} \mathrm{C}$ or less in the five minutes prior to an I-V curve. Table 8 displays the monthly power ratings, for both the ASTM and ISFOC method, for all CPV modules tested through June 2009.

Table 8. Module Power Ratings Based on ISFOC and ASTM Procedures

\begin{tabular}{|c|c|c|c|c|c|c|}
\hline Module \# & Method & 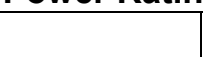 & March & April & May & June \\
\hline \multirow{6}{*}{$\begin{array}{l}\text { Module } 1 \text { installed } \\
\text { late February }\end{array}$} & \multirow[t]{3}{*}{ ISFOC* } & Power & $110.5 \mathrm{~W}$ & $111 \mathrm{~W}$ & $105.4 \mathrm{~W}$ & $96.3 \mathrm{~W}$ \\
\hline & & $\%$ S.D. $* *$ & $5.47 \%$ & $3.9 \%$ & $4.6 \%$ & $4.2 \%$ \\
\hline & & \# of data & 296 & 273 & 139 & 611 \\
\hline & \multirow[t]{3}{*}{ ASTM } & Power & $108.2 \mathrm{~W}$ & $110 \mathrm{~W}$ & $108 \mathrm{~W}$ & $97.9 \mathrm{~W}$ \\
\hline & & $\%$ S.E. $* * *$ & $5 \%$ & $4.4 \%$ & $4.6 \%$ & $2.5 \%$ \\
\hline & & \# of data & 264 & 344 & 235 & 737 \\
\hline \multirow{6}{*}{$\begin{array}{c}\text { Module } 2 \text { installed } \\
\text { mid } \\
\text { March }\end{array}$} & \multirow[t]{3}{*}{ ISFOC* } & Power & $68.1 \mathrm{~W}$ & $67.1 \mathrm{~W}$ & $68.9 \mathrm{~W}$ & $69.7 \mathrm{~W}$ \\
\hline & & $\%$ S.D. $* *$ & $4.58 \%$ & $5.66 \%$ & $2.67 \%$ & $3.9 \%$ \\
\hline & & \# of data & 83 & 274 & 141 & 599 \\
\hline & \multirow[t]{3}{*}{ ASTM } & Power & $69.5 \mathrm{~W}$ & $68.2 \mathrm{~W}$ & $69.5 \mathrm{~W}$ & $71.3 \mathrm{~W}$ \\
\hline & & $\%$ S.E. $* * *$ & $1.9 \%$ & $3.5 \%$ & $2.1 \%$ & $2.4 \%$ \\
\hline & & \# of data & 111 & 339 & 227 & 734 \\
\hline \multirow{3}{*}{$\begin{array}{l}\text { Module } 3 * * * * \\
\text { installed May }\end{array}$} & \multirow[t]{3}{*}{ ASTM } & Power & & & $77.2 \mathrm{~W}$ & $78.4 \mathrm{~W}$ \\
\hline & & $\%$ S.E. $* * *$ & & & $2.5 \%$ & $2.9 \%$ \\
\hline & & \# of data & & & 228 & 741 \\
\hline \multirow{3}{*}{$\begin{array}{c}\text { Module } 4 * * * * \\
\text { installed late May }\end{array}$} & \multirow[t]{3}{*}{ ASTM } & Power & & & $111 \mathrm{~W}$ & $110 \mathrm{~W}$ \\
\hline & & $\%$ S.E. $* * *$ & & & $1 \%$ & $2.6 \%$ \\
\hline & & $\#$ of data & & & 112 & 702 \\
\hline \multicolumn{7}{|c|}{ * Only the peak power point of each I-V curve was translated to produce these results } \\
\hline \multicolumn{7}{|c|}{ ** S.D. represents the standard deviation of power translations from the entire set of I-V curves } \\
\hline \multicolumn{7}{|c|}{$* * *$ S.E. represents the standard error of the estimate of $\mathrm{P}_{\max }$ for the regression data set } \\
\hline
\end{tabular}


Examining the data in Table 8, the two power rating procedures produce similar results. The greatest difference between the ratings for any one month is about $2.5 \%$, and this is within the standard deviation of any of the comparative ratings. It should be noted that Module 1 was removed from testing after June as a result of at least one individual cell failure. Close investigation of the data suggests that the failure occurred in the second half of May. Module 2 appears to increase in power from May to June, which coincides with an improved sun alignment (this increase is well within the standard deviation and may not be real). The ISFOC procedure was not applied to Modules 3 and 4 because the manufacturers could not provide a thermalresistance measurement for calculating cell temperature from heat-sink temperature. The difficultly in measuring or calculating cell temperature is one of the major weaknesses of the ISFOC method. The ASTM method requires no specific knowledge about the module being tested, and multiple linear regression is a valid statistical means to account for the relationship between the predictive variables and power output. Plans are to expand the comparison between ISFOC and ASTM to other modules by using $\mathrm{V}_{\text {oc }}$ measurements to calculate cell temperature. Work will also be expanded to consider other procedures for power and energy ratings. In particular, the CPV community is considering a matrix method similar to that in the flat-plate standard, IEC 61853. This procedure creates a matrix that characterizes module performance at an array of irradiances and temperatures. Questions have been raised as to what ranges of temperatures and irradiances are valid for CPV. CPERT data over both winter and summer months will be used to consider these questions and report on challenges and strengths of the method.

\subsection{Module Energy Production}

Four different CPV module technologies are currently on sun and under peak power tracking on the CPERT testbed. Power ratings at STC have been calculated for each module, but this falls short of determining how well the modules are performing. Ultimately, energy production must be considered and a simple way to do that is to calculate the ratio of energy produced to the energy incident on the modules in the form of direct-normal irradiance. Although it would be best to report $\mathrm{kWh} / \mathrm{kWh}$ data from the 1-minute averaged PPT data, due to the problems reported earlier in regard to PPT, the results are generated from the I-V data. I-V curves are taken every five minutes and only when DNI is above $250 \mathrm{~W} / \mathrm{m}^{2}$. I-V curve data were removed if sunpointing error was greater than 0.2 degree and if the DNI changed more than $10 \mathrm{~W} / \mathrm{m}^{2}$ while I-V curves were being recorded. Monthly efficiencies are reported for all modules in Table 9 as calculated by taking the ratio of $\mathrm{kWh}$ produced to DNI $\mathrm{kWh}$ incident on the module. 
Table 9. Module kWh/kWh for Monthly Data Sets

\begin{tabular}{|c|c|c|c|c|}
\hline & \multicolumn{4}{|c|}{ Monthly module efficiency } \\
\cline { 2 - 5 } & March & April & May & June \\
\hline Module 1 & 0.162 & 0.158 & 0.152 & 0.139 \\
\hline Module 2 & 0.24 & 0.239 & 0.239 & 0.244 \\
\hline Module 3 & & & 0.219 & 0.225 \\
\hline Module 4 & & & 0.221 & 0.219 \\
\hline
\end{tabular}

In addition to monthly efficiencies tabulated in Table 9, Fig. 9 displays the efficiency trend over the course of a sunny day. Figure 10 represents the DNI that accompanies the efficiencies shown in Fig. 9.

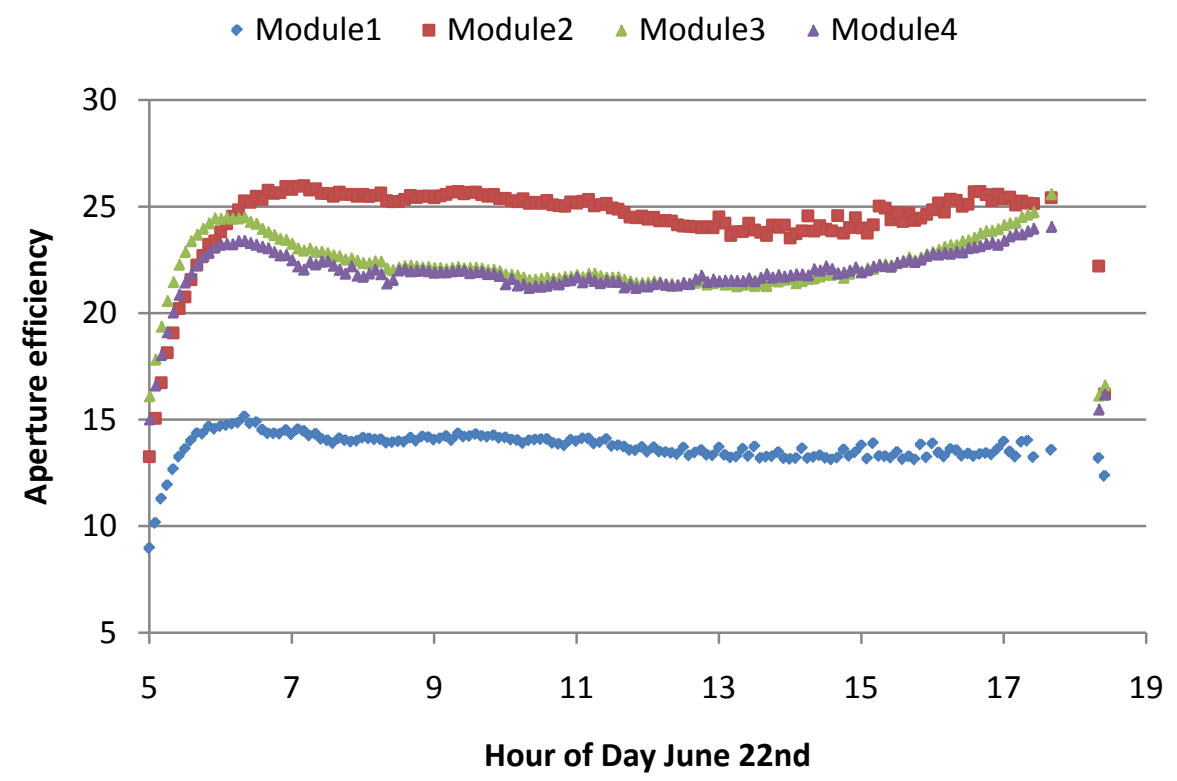

Figure 9. Module efficiency vs. time of day (June 22, 2009).

This particular day suggests that several of the modules are less efficient during the mid-day hours. Future work will examine this trend more closely for larger data sets and will look for correlations between efficiency and temperature, spectral conditions, and other possible variables. 


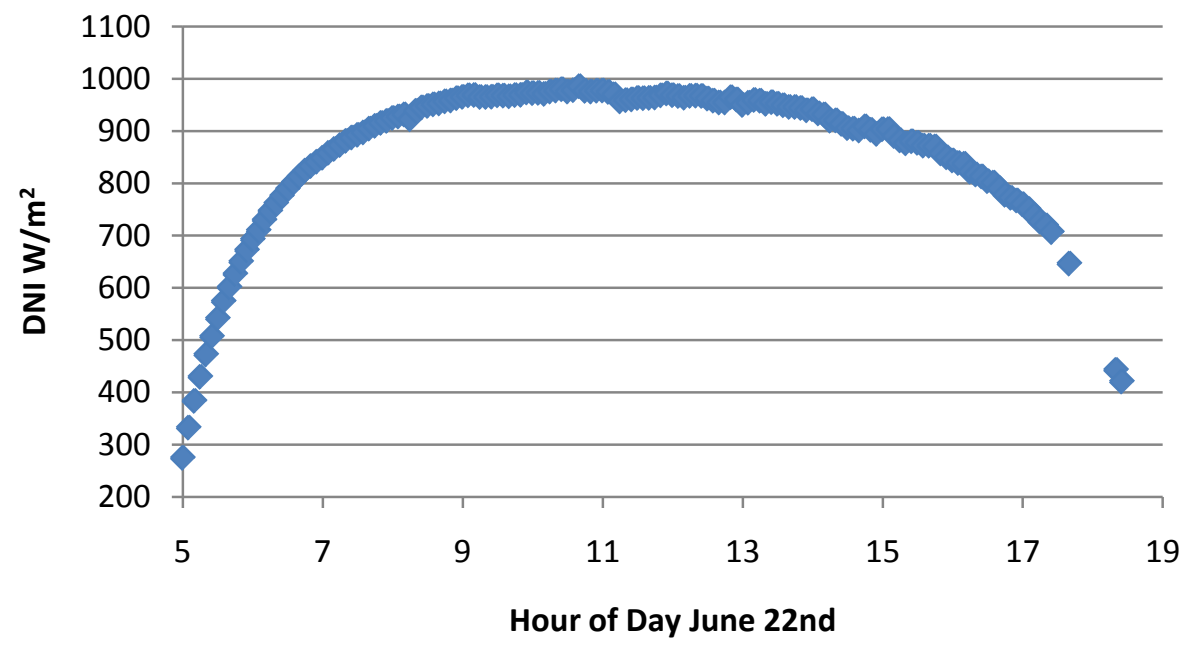

Figure 10. DNI vs. time of day (June 22, 2009).

\subsection{Conclusions and Future Work}

This report attempts to address the various aspects of setting up a CPV testbed and procedures for handling and testing CPV modules. We suggest that a CPV testbed requires a sun-tracking accuracy of at least \pm 0.25 degree, but \pm 0.05 degree is ideal. Tracking controllers associated with high-accuracy tracking are discussed. We argue that a CPV testbed must also have a TEM for verification of tracking accuracy and for data validation and filtering. DAS requirements are developed and presented in the context of current and future CPV modules. We developed a procedure for accurately aligning CPV modules on NREL's tracker.

Two power rating methods are evaluated using data from two modules. Although the methods follow very different procedures and present separate challenges, they both provide similar power ratings for each module. The monthly energy efficiency is reported for four different module technologies. The lowest monthly efficiency is $14 \%$, whereas the highest is $24 \%$. We note that the lowest monthly efficiency came from a module that was subsequently removed from testing due to a failure at the cell level. Instantaneous module efficiency is plotted over a sunny day, and two of the four modules show a nearly $2 \%$ drop in efficiency for the mid-day hours. The peak instantaneous efficiencies range from $15 \%$ to $26 \%$ for the four modules. Other than the verified cell failure in Module 1, we see no statistically significant degradation.

Future work is proposed for both the CPV testbed and in the test and evaluation of CPV modules. We are considering retrofitting the tracker with a hybrid controller to reduce tracking error to the \pm 0.05 degree range. Additional tracking-error monitors are planned to better characterize flex in the test plane and for monitoring tracking accuracy in the field. Ongoing collaboration is occurring with the DAS manufacturer to improve peak power tracking accuracy. 
CPV standards development is being following and module data will be used to evaluate the matrix method for power ratings, as well as continued evaluation of the methods listed in this report. Efficiency variations need to be closely analyzed, and SRRL data sets can be used to examine possible spectral effects on modules with triple-junction cells. Additional module technologies need to be deployed on CPERT, and all modules will be monitored for long-term degradation.

\subsection{Acknowledgements}

Appreciation is extended to Jose Rodriguez for his help in building the CPERT testbed and his continued support with PV module testing. Acknowledgements also go to Bill Marion and Sarah Kurtz for their ongoing advice and assistance with CPV work. Special thanks to Gary Galbraith for his expertise provided regarding tracking-error monitors, Chris Deline for his help with electronic control circuitry, and Joe DelCueto for his experience with multi-tracers. This work was supported by the U.S. Department of Energy under Contract No. DE-AC36-08GO28308 with the National Renewable Energy Laboratory.

\subsection{References}

1. A. Maish, The Solartrak Solar Array Tracking Controller, Sandia Report, SAND90$1471,1991$.

2. C. Ward, C. Maxey, B. Evans, and M. Lapsa, "Versatile Two-Axis Open-Loop Solar Tracker Controller," ASES 2008.

3. I. Luque-Heredia, R. Cervantes, and G. Quemere, “A Sun Tracking Error Monitor for Photovoltaic Concentrators," $4^{\text {th }}$ IEEE World Conference on Photovoltaic Energy Conversion, 2006.

4. G. Galbraith, Development and Evaluation of a Tracking Error Monitor for Solar Trackers, Sandia Report, SAND88-7025, 1988.

5. M. Martinez, F. Sanchez, J. Pachon, and P. Banda, "CPV Systems Rating, Results and Lessons Learned at ISFOC," ICSC-5, 2008.

6. ISFOC, "Specifications of General Conditions for the Call for Tenders for Concentration Photovoltaic Solar Plants at IFOC,” 2007. 


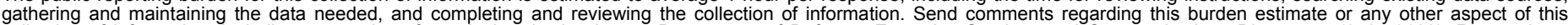

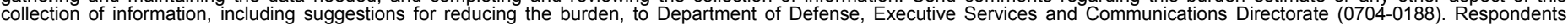

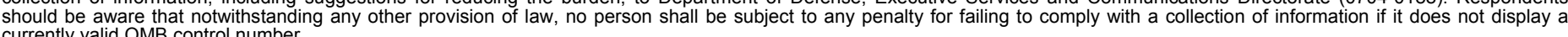

PLEASE DO NOT RETURN YOUR FORM TO THE ABOVE ORGANIZATION.

September 2009

September 2009

4. TITLE AND SUBTITLE

Development of an Outdoor Concentrating Photovoltaic Module

Testbed, Module Handling and Testing Procedures, and Initial

Energy Production Results

5a. CONTRACT NUMBER

DE-AC36-08-GO28308

5b. GRANT NUMBER

5c. PROGRAM ELEMENT NUMBER

6. AUTHOR(S)

M. Muller

5d. PROJECT NUMBER

NREL/TP-520-46569

5e. TASK NUMBER

PVD91410

5f. WORK UNIT NUMBER

7. PERFORMING ORGANIZATION NAME(S) AND ADDRESS(ES)

National Renewable Energy Laboratory

1617 Cole Blvd.

8. PERFORMING ORGANIZATION

REPORT NUMBER

Golden, CO 80401-3393

9. SPONSORING/MONITORING AGENCY NAME(S) AND ADDRESS(ES)

NREL/TP-520-46569

10. SPONSOR/MONITOR'S ACRONYM(S) NREL

11. SPONSORING/MONITORING AGENCY REPORT NUMBER

12. DISTRIBUTION AVAILABILITY STATEMENT

National Technical Information Service

U.S. Department of Commerce

5285 Port Royal Road

Springfield, VA 22161

13. SUPPLEMENTARY NOTES

14. ABSTRACT (Maximum 200 Words)

In recent years, the concentrating photovoltaic (CPV) industry has rapidly expanded as many new companies have entered the market. Each company has a unique approach aimed at making CPV a reliable, low-cost alternative to traditional flat-plate photovoltaics. As with other new technologies, a need arises to establish appropriate standards, testing requirements, and a better understanding of the technology itself. Solar Energy Technologies Program money has been awarded to some of these manufacturers, and as a result, the Test and Evaluation group at the National Renewable Energy Laboratory (NREL) has been tasked with evaluating some of the associated deliverables. To achieve this task and fulfill the above needs, NREL's Test and Evaluation group made plans to build a testbed for CPV. This report addresses the issues associated with building a CPV testbed and presents initial results from module testing. In particular, there is a focus on high-accuracy two-axis tracking, monitoring tracking error, CPV data acquisition, module handling and testing procedures, and standards development. Finally, initial power ratings and efficiency results are presented.

15. SUBJECT TERMS

PV; Outdoor Testing Facility; testbed; module; concentrating photovoltaics; two-axis tracking; testing and evaluation; tracking error; procedures; power rating; efficiency;

\begin{tabular}{|c|c|c|c|c|}
\hline 16. SECURITY & CLASSIFICATI & N OF: & 17. LIMITATION & 18. NUMBER \\
\hline $\begin{array}{l}\text { a. REPORT } \\
\text { Unclassified }\end{array}$ & $\begin{array}{l}\text { b. ABSTRACT } \\
\text { Unclassified }\end{array}$ & $\begin{array}{l}\text { c. THIS PAGE } \\
\text { Unclassified }\end{array}$ & $\begin{array}{c}\text { OF ABSTRACT } \\
\text { UL }\end{array}$ & \\
\hline
\end{tabular}

19a. NAME OF RESPONSIBLE PERSON

19b. TELEPHONE NUMBER (Include area code) 